\title{
Ovarian hyperstimulation syndrome model in mice: effect of GnRH agonist.
}

\author{
Younes Moradi ${ }^{1}$, Sara Hosseini ${ }^{2}$, Samira Mohammadi-Yeganeh ${ }^{1}$, Saghar Salehpour ${ }^{3}$, Mohammad \\ Salehi ${ }^{1,2 *}$
}

${ }^{1}$ Department of Biotechnology, School of Advanced Technologies in Medicine, Shahid Beheshti University of Medical Sciences, Tehran, Iran

${ }^{2}$ Cellular and Molecular Biology Research Center, Shahid Beheshti University of Medical Sciences, Tehran, Iran

${ }^{3}$ Departments of Obstetrics and Gynecology, Shahid Beheshti University of Medical Sciences, Tehran, Iran

\begin{abstract}
Introduction: Ovarian Hyperstimulation Syndrome (OHSS) is one of the most severe complications caused by ovarian stimulation during which the ovaries become severely stimulated and endanger an individual's health. Since the negative effects of OHSS are not really clear, an animal model was needed in order to evaluate OHSS effects on the embryo. Previous studies failed to produce any OHSS model in mouse with a large amount of oocyte. The present study aimed to evaluate the role of GnRH agonist on the number and maturation of oocytes and the preimplantation development of embryo in a mouse model of OHSS.

Method: Mice were divided into 4 groups-superovulation, OHSS with GnRH agonist and OHSS without GnRH agonist, and control. The OHSS with GnRH agonist and OHSS without GnRH agonist groups were created using the defined protocol, and, in the following stages, the oocytes were collected after euthanizing the mice and prepared for in vitro fertilization (IVF), and after performing IVF, the preimplantation development of embryos was evaluated.

Results: The results showed that, in the OHSS mouse model, the rate of oocyte maturation significantly improved in the treated GnRH agonist group comparing to the untreated GnRH agonist group. Fertilization and preimplantation development were significantly lower in the untreated GnRH agonist OHSS group.

Conclusion: With regard to the positive effects of GnRH agonist on oocyte number, oocyte maturation and preimplantation stages of embryos of mouse model, it seems that GnRH agonist can be used in order to improve the results of fertilization in the mouse model of OHSS.
\end{abstract}

Keywords: OHSS, GnRH agonist, Preimplantation development.

Accepted on May 30, 2018

\section{Introduction}

Infertility, as a condition prevailing worldwide, affects $11-15 \%$ of reproductive-age couples. Novel methods have been partially able to regulate this problem, but these methods also have various negative effects [1-4]. The Ovarian Hyperstimulation Syndrome (OHSS), the most severe complication of ovulation stimulation occurring after gonadotropin application, is one of the mentioned effects $[5,6]$. OHSS is an unwanted complication of Assisted Reproductive Technology (ART) cycles. Although the pathophysiology of this syndrome remains unknown $[3,7,8]$, it seems the applied infertility treatments using extra stimulation of gonadotropin and angiogenesis might have a key role in the occurrence of this syndrome $[7,9,10]$. The stimulation of ovaries by gonadotropins results in the secretion of vasoactive substances from ovarian glands. These products lead to an increase in the permeability of vessels and, as a result, patients reveal signs of renal failure, hypovolumic shock, and thromboambulia and adult respiratory distress [4,6-8]. Additionally, this syndrome destroys the physiological regulation between the angiogenesis stimulator and the inhibiting agents. This imbalance increases angiogenesis excessively, interrupting follicle development $[3,6,11]$.

Since this syndrome is one of the most important complications arising during infertility treatment in addition to the systematic signs mentioned above, in reproductive aspect, it leads to implantation failure, tachypnea, early abortion, renal failure and gestational diabetes [3,11-13]. Numerous studies have shown that OHSS in the primary stage leads to an increase in the incidence of chromosomal abnormalities, DNA lesion, and aneuploidy compared to the healthy group [14]. Since the negative effects of these alterations are not well known, an animal model was needed in order to evaluate the 
OHSS effects on preimplantation embryo development. Different models of OHSS are used in various studies such as the one by Chuderland et al. [6] but the problem of previous the models is that ovulation is difficult in them and they did not discuss about aspect reproductive.

The Gonadotropin Releasing Hormone (GnRH) is responsible for the control of hypothalamus secretion and biosynthesis of hypophysis gonadotropin. GnRH and its agonists lead to meiosis resumption $[15,16]$. Dekel et al. showed for the first time that special receptors were present at the surface of rat oocytes that play a key role in oocyte maturation [17]. Previous studies demonstrated that $\mathrm{GnRH}$ agonist had a significant effect on oocyte maturation directly and indirectly $[15,17,18]$. It has been shown that GnRH, having an effect on oocyte maturation, leads to a positive effect on embryonic development $[13,16,19]$. In another study, Kanter et al. indicated that GnRH agonist in superovulated mice model leads to improvements in the oocyte numbers and ovulation rate $[15,18]$.

Therefore, since the application of GnRH agonists in studies other than OHSS showed that the quality and number of oocytes were better in superovulated mice, we evaluated the effects of GnRH agonists on the creation of the OHSS mice model and, subsequently, the oocyte maturation and preimplantation development.

\section{Material and Method}

The experimental treatments were conducted in accordance with the ethical guidelines of the Animal Care and Use Committee of the Shahid Beheshti University of Medical Sciences, Tehran, Iran. All chemicals and reagents used in this research, unless otherwise stated, were purchased from Sigma Chemical Corporation (St. Louis, MO, USA).

\section{Animals}

Four-to-eight-week-old NMRI mice (Pasteur Institute, Tehran, Iran) were used in the present study. Mice were acclimatized to the laboratory conditions for $7 \mathrm{~d}$ prior to the initiation of experimental treatments. The experimental animals were housed in standard plastic cages and maintained under controlled experimental conditions of humidity (55\%), temperature $\left(22-23^{\circ} \mathrm{C}\right)$ and $12: 12 \mathrm{~h}$ light-dark cycle. Mice were fed ad libitum on normal commercial chow and had free access to water.

\section{Oocyte collection}

For preparation of oocyte, 7-8 w old NMRI female mice were selected randomly. Superovulation was induced by using $10 \mathrm{IU}$ PMSG and HCG in similar doses with 46-48 hours' intervals. Oocyte collection was done $14 \mathrm{~h}$ after the injection of HCG.

For obtaining the natural ovulated oocyte, the female mice were mated with vasectomized male mice at night. Next morning, mice with positive copulation plaque were humanely killed by cervical dislocation and their oviducts were separated and placed in Human Tubal Fluid (HTF) drops.

\section{Mouse OHSS model induction}

We established a mouse OHSS model, according to the protocol previously reported by Chuderland et al. [6] with further modification. To determine the creation of the OHSS model, we registered body and ovarian weight alteration as well as vascular permeability. Capillary permeability was measured by the Miles vascular permeability assay. Forty-eight hours after the injection of HCG, the mouse was anesthetized and $1 \mathrm{ml}$ of $5 \mathrm{Mm}$, Evans blue dye was injected intravenously. The dye binds to plasma proteins and exits from the arteries (Figure 1A). After $30 \mathrm{~min} 2 \mathrm{ml}$ of normal saline was injected intraperitoneally and the abdomen was massaged for $1 \mathrm{~min}$; then the abdominal cavity was opened, $1 \mathrm{ml}$ of the liquid was extracted and its absorbance was read at $620 \mathrm{~nm}$.
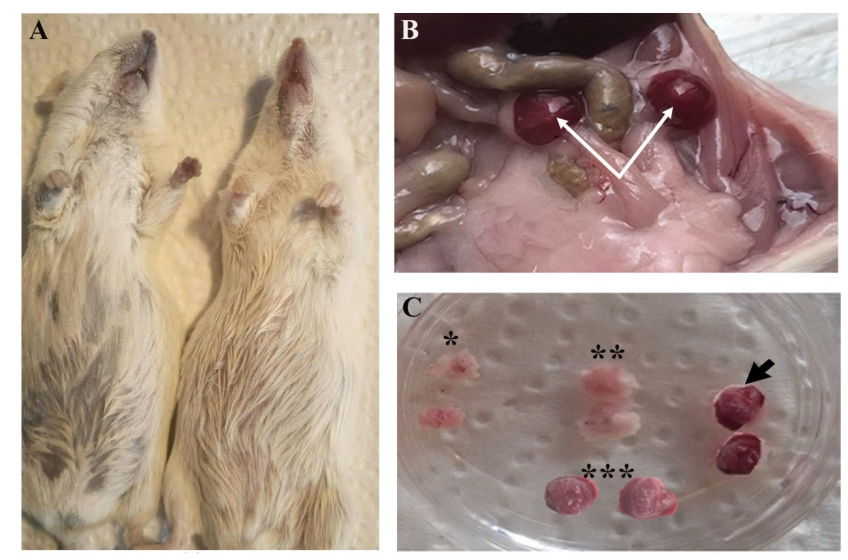

Figure 1. Induction of the murine OHSS model. A) Vascular permeability examined using Mile assay: saline-treated control and OHSS mouse model treated by Evans blue dye and fluid accumulation in the peritoneal cavity. B) Enlarged ovaries in OHSS-induced mice. C) Appearance of the ovaries in experimental groups that include control (*), superovulated (**), OHSS with GnRH (black arrow) and OHSS without GnRH (***).

Two groups of OHSS were induced: OHSS with GnRH agonist (GnRH+/OHSS) and Without GnRH (GnRH-/OHSS). Twentyfour hours before the injection of PMSG, $20 \mathrm{mg} / \mathrm{Kg} \mathrm{GnRH}$ agonist (Buserelin, Sinafact, Iran) was given by intramuscular injection. Then, 20 IU PMSG was injected on 3 consecutive days intra-peritoneally, followed by 10 IUHCG injections on the $4^{\text {th }}$ day. The cumulus mass was collected by rupturing the oviduct ampulla $13 \mathrm{~h}$ post-HCG.

The experimental groups that included control, superovulated, GnRH+/OHSS and GnRH-/OHSS groups consisted of an equal number of mice $(n=6)$.

\section{In vitro fertilization (IVF)}

In vitro fertilization was performed as a previous method [20,21]. Sperm cells were collected from $8 \mathrm{w}$ old NMRI male mice. The epididymis was separated and the sperm cells were 
transferred to a dish containing Human Tubal Fluid (HTF) media supplemented with $4 \%$ BSA. Then, it was incubated for $45 \mathrm{~min}$ at $37^{\circ} \mathrm{C}$ and $5 \% \mathrm{CO}_{2}$. Sperms were added to the HTF media containing cumulus oocyte complex and incubated for 6 h. The presumable zygotes were extracted from the HTF media and transferred to the KSOM medium containing 4\% BSA and cultured in $5 \% \mathrm{CO}_{2}$ at $37^{\circ} \mathrm{C}$ for $96 \mathrm{~h}$. The fertilization rate and blastocyst formation were calculated.

\section{Statistical analysis}

The data were analysed using the SPSS 22 for Windows (SPSS, Chicago, IL, USA). The mean of the data were assessed by one-way Analysis of Variance (ANOVA) and post hoc Tukey test. Differences were considered statistically significant at $\mathrm{P}<0.05$.

\section{Result}

\section{Mouse OHSS model confirmation}

We assessed body weight, ovarian weight; and vascular permeability to verify the OHSS model. Enhanced micro vascular permeability and its related edema that resulted in increased body weight along with ovary enlargement confirmed the OHSS model in mice (Figures 1B and 1C). We observed the maximum percentage of weight gain in the GnRH-/OHSS group $(15 \%, p<0.05)$. Similarly, weight gain increased substantially in GnRH+/OHSS group by around $8 \%$ compared to the superovulated and control groups. As can be seen from Figure 2A, the ovary weight in both OHSS groups was significantly higher than other groups. Figure $1 \mathrm{C}$ shows that the permeability index in OHSS induced-mice $\mathrm{GnRH}+/$ OHSS and GnRH-/OHSS has dramatically increased compared to those of superovulated and control groups $(\mathrm{p}<0.05)$.

\section{Oocyte maturation rate}

Table 1 represents details of the developmental stages of obtaining oocyte in different groups from NMRI mice.

The results showed that the percentage of GV $(43.05 \pm 6.36)$ and MI oocytes (18.05 \pm 3.67$)$ in GnRH-/OHSS significantly increased compared to other groups. The higher percentage of MII oocytes belonged to GnRH+/OHSS about $87.72 \pm 6.43 \%$.

\section{Fertilization and preimplantation development}

In vitro fertilization was performed to compare the rate of fertilization and preimplantation development among control, superovulated, OHSS with GnRH agonist and OHSS without GnRH agonist oocytes. Details are shown in Table 2.

The results showed that the fertilization rate $(53.32 \pm 10.18)$ and blastocyst formation $(17.66 \pm 9.68)$ in the OHSS without GnRH group was significantly lower than other groups. Additionally, there was a significant decline in the cleavage rate in the OHSS groups compared to control and superovulated groups.
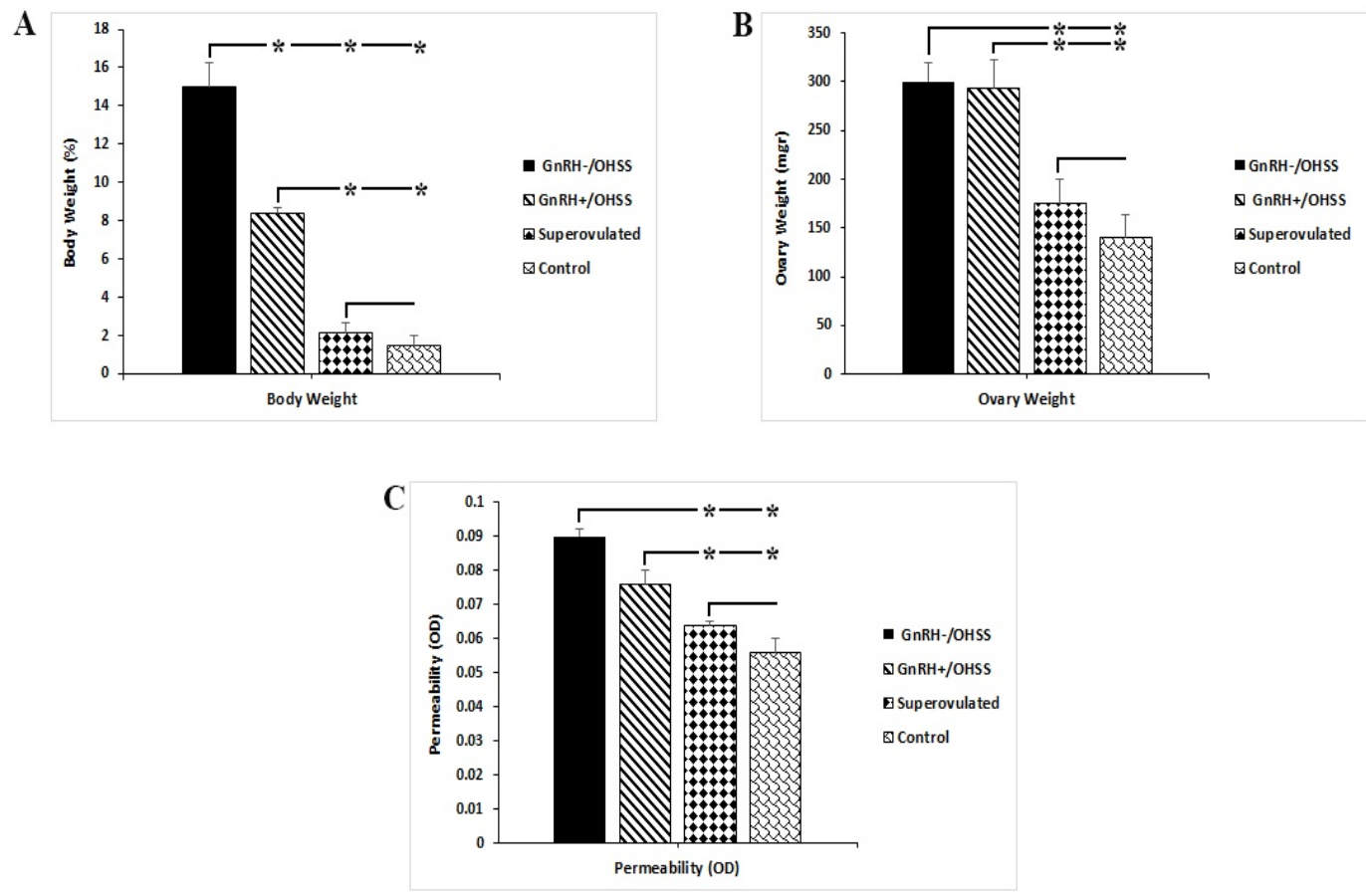

Figure 2. OHSS induction criteria. A) Body weight alteration ( $g$ ) was monitored to evaluate edema formation that is attributed to OHSS. B) Ovarian weight was recorded after mice were killed by cervical dislocation. C) The vascular permeability was evaluated with the Evans blue dye. Dye absorbance in abdominal fluid was read at $620 \mathrm{~nm}\left({ }^{*} p<0.05\right)$. 
Table 1. Oocytes maturation rate in different groups studied.

\begin{tabular}{|c|c|c|c|c|}
\hline Group & No.of oocytes & GV\% (mean \pm SD) & MI\% (mean \pm SD) & MII \% (mean \pm SD) \\
\hline Control & 60 & $8.29 \pm 2.72^{a}$ & $15.07 \pm 5.4^{a}$ & $76.63 \pm 7.91^{a}$ \\
\hline Superovulated & 101 & $5.72 \pm 1.89^{a}$ & $7.30 \pm 3.06^{a}$ & $86.96 \pm 1.19^{a}$ \\
\hline $\mathrm{GnRH}+/ \mathrm{OHSS}$ & 79 & $7.08 \pm 6.24^{a}$ & $5.19 \pm 2.31^{a}$ & $87.72 \pm 6.43^{a}$ \\
\hline GnRH-/OHSS & 28 & $43.05 \pm 6.36^{b}$ & $18.05 \pm 3.67^{b}$ & $38.88 \pm 2.40^{\mathrm{b}}$ \\
\hline
\end{tabular}

Within the same column, values with different letters were significantly different $(p<0.05)$. GV: Germinal Vesicle Oocyte; MI: Metaphase I Oocyte; MII: Metaphase II Oocyte.

Table 2. Preimplantation development status in experimental groups.

\begin{tabular}{|c|c|c|c|c|c|}
\hline Group & Two-cell stage & Four-cell stage & Eight-cell stage & Morula & Blastocysts \\
\hline Control & $95.47 \pm 2.32^{a}$ & $86.66 \pm 3.85^{a}$ & $82.61 \pm 3.94^{a}$ & $78.09 \pm 2.20^{\mathrm{a}}$ & $76.00 \pm 3.95^{a}$ \\
\hline Superovulated & $91.48 \pm 2.83^{a}$ & $84.92 \pm 3.29^{a}$ & $78.20 \pm 4.33^{a}$ & $74.52 \pm 5.41^{\mathrm{a}}$ & $71.90 \pm 4.79^{a}$ \\
\hline $\mathrm{GnRH}+/ \mathrm{OHSS}$ & $84.98 \pm 2.50^{\mathrm{a}}$ & $64.85 \pm 4.85^{\mathrm{b}}$ & $49.06 \pm 3.93^{b}$ & $43.17 \pm 2.29^{b}$ & $37.54 \pm 1.89^{b}$ \\
\hline GnRH-/OHSS & $53.32 \pm 10.18^{b}$ & $46.33 \pm 11.01^{b}$ & $24.33 \pm 12.37^{c}$ & $24.33 \pm 12.37^{c}$ & $17.66 \pm 9.68^{c}$ \\
\hline
\end{tabular}

Within the same column, values with different letters were significantly different $(p<0.05)$.

\section{Discussion}

Different studies on human and animal models have shown that in OHSS, some mediatory compounds are released from the ovaries that increase capillary permeability and liquid assembly in the peritoneal cavity $[2,22,23]$. Although the pathophysiology of this syndrome is not completely revealed, it seems that the release of vasoactive and angiogenic substances lead to leakage, hyperpermeability of liquid and shift of fluids from blood vessels into the extravascular space and have a role in this syndrome [24-26]. One of the most important signs of this syndrome is the enlargement of ovaries in which luteal and hemorrhagic cysts along with a shift of liquids into the peritoneal cavity. Polishuk et al. reported that the release of various compounds from the ovaries leads to an increase in capillary permeability and, hence, liquid shift from the intravascular compartment into the peritoneal cavity [2,27].

Ohba et al. showed that the weights of ovary and peritoneal fluid were higher in the OHSS group compared to the control group, results that are consistent with those of our study [28]. Enhanced micro vascular permeability and its related edema that resulted in increased body weight along with ovary enlargement confirmed the OHSS model in mice.

Recently, it has been shown that GnRH agonist, in addition to its conventional effect on gonadotropins, plays various roles in reproduction; this hormone is effective in the fertilization rate and gestation results directly and indirectly by having an effect on follicle and oocyte development. In the present study, the effect of GnRH agonist on reproductive indices of the OHSS mouse model has been evaluated. These effects were compared with the control and superovulated groups. Our results demonstrated that, in the OHSS mouse model, the number and maturation rate of oocyte in the $\mathrm{GnRH}+/ \mathrm{OHSS}$ group was significantly improved compared to the GnRH-/OHSS group.
Numerous studies indicate the effect of GnRH on oocyte number following conventional ovarian stimulation, though no study was found to show this effect in OHSS. Coskun et al. showed that GnRH agonists led to significant increase in the number and quality of oocytes in target group compared to superovulate and control groups [16]. Kanter et al. evaluated the effect of GnRH on number and maturation of oocytes in superovulate mice, they showed that the injection of GnRH before superovulation resulted in a significant increase in the ovulation rate, oocyte number, maturation, and the number of corpora lutea [15]. We reported the effect of GnRH on number and maturation of oocytes in the OHSS mice model for the first time. Different possible reasons can be cited for a positive impact of GnRH on oocyte development: 1) It has been shown that GnRH with effect on hypophysis leads to the regulation of synthesis and release of gonadotropins; these compounds are effective in oocytes maturation and ovulation by having an effect on ovaries. 2) Cytokines such as the Vascular Endothelial Growth Factor (VEGF), Tumor Necrotic Factoralpha (TNF- $\alpha$ ), basic Fibroblast Growth Factor (bFGF), Interleukin-8 (IL-8), IL-6, IL-1 $\beta$ etc., can be effective in the incidence of OHSS [2,19]. Among these factors, VEGF is of crucial importance in OHSS because of its proven effect on angiogenesis. Furthermore, the amount of this cytokine increases significantly after stimulation of ovaries with HCG administration and has a high effect on endothelial cell permeability and somehow is effective in the creation and advancing of OHSS. The studies have shown that in patients with OHSS, the amount of VEGF and its receptors is higher compared to individuals without this disorder. Kitajima et al. reported that, in the OHSS animal model, treatment with GnRH decreased the capillary permeability via VEGF reduction and its receptors [29]. Therefore, in this way, GnRH can prevent early incidence and advancing of OHSS. It seems that $\mathrm{GnRH}$ can be effective in the maintenance of ovary 
structure and function and, hence, the number of released oocytes is higher in OHSS mice receiving GnRH compared to those that did not receive GnRH. 3) It has been shown that $\mathrm{GnRH}$, by increasing ovarian blood circulation, leads to the establishment of regulation between intra and extra-cellular liquids, which leads to the creation of hemodynamic regulation in ovary and, therefore, maturation of oocytes. 4) Taylor et al. showed that GnRH agonists are effective in primate follicle development and angiogenesis [30]. In addition $\mathrm{GnRH}$, with its direct effect on granulosa cells, leads to stimulation of follicle growth and their maturation. 5) Previous studies have indicated various roles of $\mathrm{GnRH}$ including an increase in prostaglandin stimulation at the onset of meiosis that has an influence on oocytes maturation.

The results of our study show that fertilization and preimplantation development of GnRH-/OHSS and $\mathrm{GnRH}+/$ OHSS were significantly lower than other experimental groups. Although the number of oocytes improved using $\mathrm{GnRH}$ agonist in OHSS, the developmental competence of oocytes was found to be less than those of the control and superovulate groups, indicating the effects of overstimulation of OHSS on the development of preimplantation embryo development.

To summarize, injection of GnRH agonist $24 \mathrm{~h}$ before OHSS induction led to an increase the in number and developmental competences of oocyte. However, more studies are needed to evaluate the maturation of ovulated oocytes under the effect of GnRH agonist in the OHSS model.

\section{Acknowledgments}

This study was extracted from the Ph.D. thesis of Younes Moradi and was supported by Shahid Beheshti University of Medical Sciences, Tehran, Iran. The authors gratefully thank Maryam Dehghani-Mohammadabadi and Shokofe Torabi for providing all supports.

\section{References}

1. Agarwal A, Mulgund A, Hamada A, Chyatte MR. A unique view on male infertility around the globe. Reproduct Biol Endocrin 2015; 13: 37.

2. Alama P, Bellver J, Vidal C, Giles J. GnRH analogues in the prevention of ovarian hyperstimulation syndrome. Int J Endocrin Metabol 2013; 11: 107.

3. Rau 1 Go mez, Sergio RS, Cristiano B, Juan AGV, Carlos S, Antonio P. Physiology and pathology of ovarian hyperstimulation syndrome. Semin Reprod Med 2010; 28: 448-457.

4. Annick D, Rozenberg S. Review of clinical course and treatment of ovarian hyperstimulation syndrome (OHSS). Human Reproduction Update 2003; 9: 77-96.

5. Kumar P, Sait SF, Sharma A, Kumar M. Ovarian hyperstimulation syndrome. Hum Reproduct Update 2011; 4: 70.

6. Chuderland D, Ben-Ami I, Kaplan-Kraicer R, Grossman H, Ron-El R, Shalgi R. The role of pigment epithelium- derived factor in the pathophysiology and treatment of ovarian hyperstimulation syndrome in mice. $\mathrm{J}$ Clin Endocrin Metabol 2013; 98: 258-266.

7. Nastri C, Teixeira D, Moroni R, Leitao V, Martins W. Ovarian hyperstimulation syndrome: pathophysiology, staging, prediction and prevention. Ultrasound Obstetrics Gynecol 2015; 45: 377-393.

8. Sansone P, Aurilio C, Pace MC, Esposito R, Passavanti $\mathrm{MB}$, Pota V. Intensive care treatment of ovarian hyperstimulation syndrome (OHSS). Annal New York Acad Sci 2011; 1221: 109-118.

9. Wei LH, Chou CH, Chen MW, Rose-John S, Kuo ML, Chen SU. The role of IL-6 trans-signaling in vascular leakage: implications for ovarian hyperstimulation syndrome in a murine model. J Clin Endocrinol Metabol 2013; 98: 472-484.

10. van de Lagemaat R, Raafs B, Van Koppen C, Timmers C, Mulders S, Hanssen R. Prevention of the onset of ovarian hyperstimulation syndrome (OHSS) in the rat after ovulation induction with a low molecular weight agonist of the LH receptor compared with hCG and rec-LH. Endocrinol 2011; 152: 4350-4357.

11. Humaidan P, Nelson S, Devroey P, Coddington C, Schwartz L, Gordon K. Ovarian hyperstimulation syndrome: review and new classification criteria for reporting in clinical trials. Hum Reproduct 2016; 31: 1997-2004.

12. Wiser A, Levron J, Kreizer D, Achiron R, Shrim A, Schiff E. Outcome of pregnancies complicated by severe ovarian hyperstimulation syndrome (OHSS): a follow-up beyond the second trimester. Hum Reproduct 2005; 20: 910-914.

13. Fossum GT, Davidson A, Paulson RJ. Ovarian hyperstimulation inhibits embryo implantation in the mouse. J Fertil Embryo Transfer 1989; 6: 7-10.

14. Santos MA, Kuijk EW, Macklon NS. The impact of ovarian stimulation for IVF on the developing embryo. Reproduction 2010; 139: 23-34.

15. Kanter M, Yildiz C, Meral I, Koc A, Tasal I. Effects of a $\mathrm{GnRH}$ agonist on oocyte number and maturation in mice superovulated with eCG and hCG. Theriogenology 2004; 61: 393-398.

16. Coskun O, Kanter M. GnRH agonist stimulates oocyte number and maturation in mice superovulated with eCG and hCG. Ann N Y Acad Sci 2005; 2: 1-4.

17. Nava D. Regulation of oocyte maturation. Ann N Y Acad Sci 1988; 541: 211-216.

18. Yang BC, Uemura $\mathrm{T}$, Minaguchi $\mathrm{H}$. Effects of a gonadotropin releasing hormone agonist on oocyte maturation, fertilization, and embryonal development in mice. J Assist Reproduct Gen 1995; 12: 728-732.

19. Elchalal U, Schenker JG. The pathophysiology of ovarian hyperstimulation syndrome-views and ideas. Hum Reproduct 1997; 12: 1129-1137.

20. Dehghani-Mohammadabadi M, Salehi M, Farifteh F, Nematollahi S, Arefian E, Hajjarizadeh A. Melatonin modulates the expression of BCL-xl and improve the 
development of vitrified embryos obtained by IVF in mice. J Assist Reproduct Gen 2014; 31: 453-461.

21. Hosseini S, DehghaniMohammadabadi M, Ghafarri Novin M, Haji Molla Hoseini M, Arefian E, Mohammadi Yeganeh S. Tolllike receptor4 as a modulator of fertilization and subsequent preimplantation development following in vitro maturation in mice. Am J Reproduct Immun 2017; 78.

22. Fainaru O, Hornstein MD, Folkman J. Doxycycline inhibits vascular leakage and prevents ovarian hyperstimulation syndrome in a murine model. Fertil Steril 2009; 92: 1701-1705.

23. Ujioka T, Matsuura $\mathrm{K}$, Tanaka $\mathrm{N}$, Okamura $\mathrm{H}$. Involvement of ovarian kinin-kallikrein system in the pathophysiology of ovarian hyperstimulation syndrome: studies in a rat model. Hum Reproduct 1998; 13: 3009-3015.

24. Bates D, Hillman N, Williams B, Neal C, Pocock T. Regulation of microvascular permeability by vascular endothelial growth factors. J Anat 2002; 200: 581-597.

25. Gomez R, Simon C, Remohi J, Pellicer A. Administration of moderate and high doses of gonadotropins to female rats increases ovarian vascular endothelial growth factor (VEGF) and VEGF receptor-2 expression that is associated to vascular hyperpermeability. Biol Reproduct 2003; 68: 2164-2171.

26. Goomez R, Simoon C, Remohii J, Pellicer A. Vascular endothelial growth factor receptor-2 activation induces vascular permeability in hyperstimulated rats, and this effect is prevented by receptor blockade. Endocrinology 2002; 143: 4339-4348.

27. Polishuk W, Schenker J. Ovarian overstimulation syndrome. Fertil Steril 1969; 20: 443-450.

28. Ohba T, Ujioka T, Ishikawa K, Tanaka N, Okamura H. Ovarian hyperstimulation syndrome-model rats; the manifestation and clinical implication. Mol cell Endocrinol 2003; 202: 47-52.

29. Kitajima Y, Endo T, Nagasawa K, Manase K, Honnma H, Baba T. Hyperstimulation and a gonadotropin-releasing hormone agonist modulate ovarian vascular permeability by altering expression of the tight junction protein claudin-5. Endocrinol 2006; 147: 694-699.

30. Taylor P, Hillier S, Fraser H. Effects of GnRH antagonist treatment on follicular development and angiogenesis in the primate ovary. J Endocrinol 2004; 183: 1-17.

\section{*Correspondence to}

Mohammad Salehi

Department of Biotechnology

School of Advanced Technologies in Medicine

Shahid Beheshti University of Medical Sciences

Iran 